cross-named oblique. Thus in looking downwards and to the left-i.e., to the left inferior area-the patient uses his left inferior rectus and his right superior oblique.

We are now in a position to consider the diplopia which will arise from an ocular paralysis. The chief symptoms of under-action of an ocular muscle are: 1. Limitation of movement of the affected eje in some one direction. As they move together in that direction one of the two lags more and more behind the other, producing a continually increasing deviation. This gives rise to (2) diplopia, which is most marked of course in that position of the eyes towards which the affected muscle, when normal, moves the eye. The false image is always in the direction of the action of the paralysed musole. 3. Altered position of the head. In order to avoid diplopia as far as possible the face assumes a position similar to that which the eye would take were the paralysed muscle to act upon it. In fact, the face looks in the direction of greatest diplopia. Thus the face looks towards the right with a right external or a left internal paralysis.

It is now an easy matter to determine the particular muscle affected in a given case by noting the diplopia which occurs on moving a candle to the right, to the left, upwards and downwards in front of the patient. If the diplopia is increased-i.e., if the separation of the image is increased-in more than one of these directions an affection of. more than one muscle is indicated. It is important to avoid forming one's diagnosis upon the observed inclination of the false image, for a previous heterophoria may render one's conclusions erroneous. The procedure which adopt is really an epitome of the methods described by $\mathrm{Mr}$. Maddox in his book on the Ocular Muscles and is indicated below. I have found it simple, free from pitfalls, and logical. Just as "a botanist with a flower inquire successively into its natural order, its genus and its species," so the ophthalmologist reaches his diagnosis by stages, determining first whether the muscle at fault belongs to the order $\mathbf{A}, \mathbf{B}$, or $\mathbf{C}$, then the genus $a$ or $b$, by noting if the separation of the images is increased by moving the candle to the right or to the left. By placing a red glass before the right eye we can at once determine which eye, and therefore which muscle, is at fault. All that one has to do in a case of vertical diplopia is to determine in which area of the patient's field of view the greatest vertical separation occurs and "the paralysed muscle is either the same-named rectus or the oross-named oblique." Thus if the greatest vertical separation occurs in the right inferior area the paralysed muscle must be either the right inferior rectus or the left superior oblique. This is Mr. Maddox's mnemonic and $I$ have found that it is readily grasped by students and is never forgotten. The use of a red glass before the right eye distinguishes the two quite simply by means of the appended table.

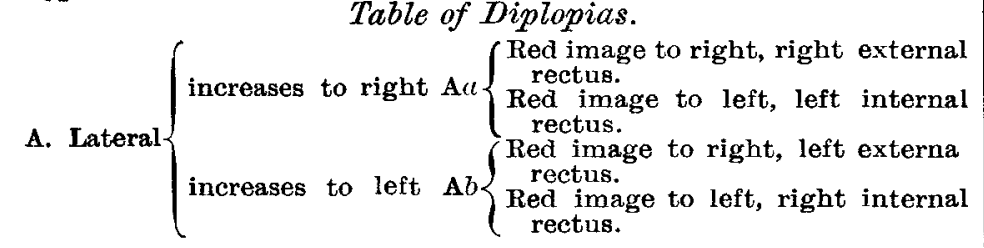

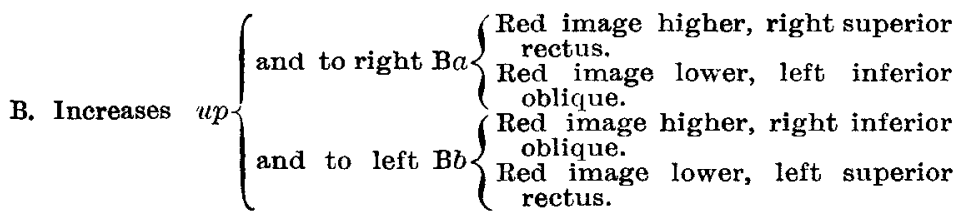
C Increases down $\left\{\begin{array}{l}\text { and to right } \mathrm{C} a\left\{\begin{array}{l}\text { Red image higher, left superior } \\ \text { oblique. } \\ \text { Red image lower, right inferior } \\ \text { rectus. }\end{array}\right. \\ \text { and to left } \mathrm{Cb}\left\{\begin{array}{l}\text { Red image higher, left inferior } \\ \text { rectus. } \\ \text { Red image lower, right superior } \\ \text { oblique. }\end{array}\right.\end{array}\right.$ Newcastle-on-Tyne.

The Queen's Jubilee Hospital.-We have received information from the matron of the Queen's Jubilee Hospital that she, a sister, and the staff-nurse have resigned their situations at the institution.

Small-Pox Hospital at Devonport.-A smallpox hospital has been erected by the isolation hospital subcommittee of the Devonport town council, at a cost of about $£ 500$. The building is of wood and iron and will accommodate 12 patients-six males and six females.

\section{A NOTE ON THE CONDITION OF PATIENTS AFTER THE REMOVAL OF THE VERMIFORM APPENDIX.}

By LAWRENCE JONES, M.S. LOND., F.R.C.S. ENG., SURGICAL REGISTRAR TO ST. GEORGE'S HOSPITAL.

IN the early part of this year I took the trouble to write to all those patients upon whom operations had been performed for appendicitis at St. George's Hospital in the years 1900, 1901, and 1902, with a view to ascertain how many of them were entirely satisfied with their condition and how many suffered from ailments, trivial or severe, which they referred to the region of the operation. It was impossible to see all the patients personally and the majority of them only eommunicated with me by letter, but, notwithstanding this, their answers are, for the most part, sufficiently full and of interest. Information was especially asked for on the following points: (1) the existence of pain, constipation, flatulence, \&c., as being possibly caused by adhesions; (2) tenderness of the scar; and (3) ventral hernia. The number of letters despatched was 184 and from these resulted 87 replies. These 87 may be separated according to the condition of the patient at the time of operation into three groups: (1) those in whom the peritoneum had become infected, with a resulting abscess or generalised peritonitis ; (2) those with a definite acute attack at the time of operation but with no suppuration outside the appendix; and (3) those upon whom operation was performed in a quiescent period or during a subacute attack. To deal with these groups separately.

1. In some of the cases in which there was definite sup puration around the appendix the viscus was removed during the patients' stay in the hospital, while in others the abscess cavity was merely drained, the appendix being left untouched. Considering these two classes apart, the first included 22 patients, and of these 12 could mention no defect in their present health, three suffered with slight occasional local pain, three had noticed some bulging of the scar, one was more constipated than formerly, and one was more flatnlent. Two ascriber definite lesions to the operation : the first had become ruptured in both groins, an effect, he considered, of his abdominal scar; the second, whose scar had "reopened " after leaving the hospital, wrote pages describing various vague complaints and has probably developed a ventral hernia. Of these two the former has no proper ground of complaint.

Among the patients whose appendices had not been removed two developed an acute attack later and underwent removal of the offending organ and are now quite well. Nine are in perfect health, although the appendix is still, presumably, in the right iliac fossa; six could mention the usual milder troubles which, however, failed to inconvenience them seriously, and included pricking pain with bulging of the scar, femoral thrombosis which has since cleared up, slight bulging of the scar, abscess of the scar, and, in two cases, pain on exertion.

2. The patients, upon whom operations had been performed during an acute attack but before obvious peritoneal infection had occurred, numbered 16 , and in no case did any of these instance trouble sufficiently severe to incapacitate them in any way. 12 were in perfect health; in one case the scar was slightly tender on pressure, in two others there was slight pain with some fulness in the scar, and in the fourth there was a definite hernia at the site of operation as large as a hen's egg.

3. Those patients operated upon during a subacute attack or in a quiescent period were 32 in number and furnished the following replies. 20 expressed themselves as being better in every way and much benefited by the operation, nine could find some symptoms which they thought possibly due to the scar-for example, four had noticed slight occasional pain on exertion or on coughing, one suffered from constipation, one from "flatulent dyspepsia," another from tenderness in the scar, and three thought that the scar showed more prominently than before.

Three patients wrote letters which seemed to show signs of their dissatisfaction with their present lot; the first, a woman whose appendix had been removed for recurrent attacks of appendicular colic and whose wound had supparated, has since developed a large ventral hernia and has 
been treated for anæmia, gastric ulcer, parametritis, and various other disorders. The other two complained of acute pain at times in the region of the operation, sufficiently severe to be a burden to them but not enough ever to prevent their ordinary occupations. Both of these were operated on after several attacks, and in one case the appendix was found firmly bound down by many adhesions and with its lumen obliterated by old inflammation, so that their trouble is probably due to the formation of adhesions prior to the operation.

Taking these three classes together, it will be seen that out of 87 patients 54 have been in a perfectly normal state of health -ince their discharge from the hospital; 27 wrote to say that although their health has been good, yet symptoms have aris $n$ from time to time which have attracted their attention to the wound; and six wrote as though they had definite grounds for the complaint of ill-health since the operation. Of these six, three have unquestionable ventral herniæ, two suffer from severe occasional pain, and one charges the operation with an effect which it probably could not have produced.

Dealing with the symptoms which have been mentioned in order: bulging of the scar or ventral hernia appears on 13 oscasions; in three only is it stated to be a definite hernia, in the other ten the condition is briefly alluded to as "fulness or prominence" of the scar. In one of these ten it seems so marked that the number of definite herniæ may be increased to four; while of the other nine the condition may be assumed to be merely either a weakness of the scar without any definite hernia or else the natural prominence of an abdominal scar. Local pain was found to occur in 17 patients. Out of these, 13 alluded to it as being " a pricking pain, occasionally, on exertion," or words to that effect; and of the other four it was only severe in two. Tenderness of the scar, constipation, flatulence, and the formation of an abscess in the scar after the patient's discharge were noted each on two occasions, and in one, thrombosis, which had delayed the man's convalescence in the hospital, had recurred since.

The total cases may again be divided into 44 in which drainage was employed and 43 in which the wounds were closed. Of the former group 25 are quite well and 19 have some troubles, mild or severe; of the latter 29 are well and 14 have now, or have had, some symptoms. The difference between the two does not seemed marked; but out of the cases which complained of bulging, weakness, or definite hernia of the scar nine belong to the fo:mer and four to the latter group, and of these four it was apparently only a genuine hernia in two, in both of which the wound had suppurated. It is therefore apparent that the risk of hernia, provided the wound runs an aseptic course and provided that it can be completely closed, is slight, in spite of the fact that in many of the above cases the deeper structures were only brought together by one layer of sutures.

The number of patients is too small to allow one to form any definite opinion of the conditions with which one may expect to meet after the operation for appendicitis, and at first sight the proportion of patients who can adduce symptoms which did not exist before its performance seems unexpectedly large, but the tone of the letters, with one or two exceptions, betrays a gratitude which shows how little the writers are inconvenienced. It also appears that the subjects of definite suppuration in whom the appendix was not removed are in no worse a condition than those deprived of that organ in the first instance, but it must be remembered that of the former 17 two ran a definite risk to life by subsequently incurring another attack. Small though the number of cases be, it shows that after-results are far less common among patients in whom the appendix is removed early in the first acute attack than when the case is allowed to go on to suppuration or to the formation of adhesions consequent upon recurrence of the disease.

I am much indebted to the staff of St. George's Hospital for permission to make use of their cases.

Grosvenor-street, W.

Pilkington Cancer Research Endowment.We have been asked to remind our readers that applications for appointment under this endowment will be received up to Wednesday, Dec. 13th, by Professor G. A. Wright, Victoria University, Manchester, from whom all particulars can be obtained if any further than those stated in our recent annotation are required.

\section{DE SENECTUTE.}

\section{By Sir SAMUEL WILKS, BART., M.D. LOND., F.R S.}

THE subject of old age having lately been much before the public owing to some very startling doctrines said to have been enunciated by Dr. W. Osler, the new Regius professor of medicine at Oxford, I have naturally had my attention turned in that direction and now with your permission will lay my thoughts before your readers. I shall refer both to the physical and mental changes which occur as age advances-that is, to those changes felt consciously and personally and then to those which are observed by others. I have noticed in the correspondence which the interest of the subject has called forth that reference has, for the most part, been made to the mental side and therefore mainly to the ages at which anthors have first given their principal works to the world.

The heading of my paper will naturally remind my readers of the well-known essay of Cicero. This I have always considered to be not very satisfactory, for although powerful and truthful, it is drawn from his observations of others rather than from an introspection of himself. The great orator, it must be remembered, wrote under the pseudonym of Cato who was supposed to be 84 years of age, whilst Cicero himself was only about 60 years-that is to say, 20 years younger. He therefore could not possess the personal experience of a very old man. I cannot for this reason quite put myself in Cicero's place when personally I reckon $m$ y years only a little less than those of the imaginary sage. As regards the subjective and objective methods of inquiry on the question of age, the former is often of little value compared with the latter and, indeed, is sometimes as different from it as are the opposite sides of the shisld.

I remember once talking to Sir James Paget on this subject and his conclusions were that no one was ever conscious of old age, or rather he had no consciousness or feeling which was always reminding him of the period of life which he had reached. Even very precocious children never realise the fact that they are in the position of their seniors. So Sir James Paget maintained that we had no conscious knowledge of advancing age but discovered it in the same way as our friends and others do, by contemplation and observation, by thinking of our past career, remembering the dates of certain events, counting our wrinkles in the looking-glass, or gazing at our shrivelled hands. So little, indeed, do many per:ons remember their age that they have to think and reckon up their years before they can give the correct answer. I might illustrate this subject by mentioning my own case. Knowing how little we realise our advancing years I was continually counting mine and contemplating what the result would be on the future actions of my life. I think mine is a very exceptional case but it occurred from having observed how many persons whom I had known had been the victims of self-deception or senile vanity, and I thought I would be on my guard. I therefore acted in several cases in accordance with my years instead of asking myself what capabilities of work I still had within me. I have no doubt I erred on the side I took, although the error, I think, was a very exceptional one. Having retired from my hospital according to rule at 60 years of age and at the same time giving up some of my practice I began to regard myself as having arrived at $m y$ climax and that I had already begun my descent. I took this view as the most reasonable, wishing to guard myself against the inroads of self-deception. So regarding myself from this outside point of view I continually spoke of my inability to hold any more public positions and declared that I was passé. When, however, I was put into harness and kept it on for three years I was informed that I had performed the duties of my important position very well. Of this I was scarcely conscious, so that if the verdict had been a contrary one I should have equally accepted it. I confess that in endeavouring to avoid the rocks I had fallen into the whirlpool and had not sufficiently relied on the powers which I had still retained. I mention this personal narrative because $I$ think it has a bearing upon the question which $I$ am discussing.

In spite of this admission I am much in accord with Professor Osler's statement if taken in its true signification. When he spoke of the failing powers of age he did ko in such 